1 Universidade Federal de Santa Catarina (UFSC), Programa de Pós-Graduação em Saúde Coletiva - Florianópolis (SC), Brasil.

pvmiclos@gmail.com

2 Universidade Federal de Santa Catarina (UFSC), Departamento de Saúde Pública e Programa de Pós-Graduação em Saúde Coletiva - Florianópolis (SC), Brasil.

cristina.clv@gmail.com

3 Universidade Federal de Santa Catarina (UFSC), Departamento de Saúde Pública e Programa de Pós-Graduação em Saúde Coletiva - Florianópolis (SC), Brasil.

claudia.colussi@ufsc.br

\section{Avaliação do desempenho da Atenção Básica nos municípios brasileiros com indicador sintético}

\author{
Performance evaluation of Primary Care in Brazilian municipalities \\ with Synthetic Indicator
}

Paula Vitali Miclos ${ }^{\mathbf{1}}$ Maria Cristina Marino Calvo ${ }^{\mathbf{2}}$, Claudia Flemming Colussi ${ }^{\mathbf{3}}$

RESUMO O objetivo foi avaliar o desempenho da Atenção Básica nos municípios brasileiros. Utilizou-se o indicador sintético proposto pelo modelo de avaliação da Atenção Básica - Núcleo de Extensão e Pesquisa em Avaliação em Saúde. Avaliou-se a dimensão de Provimento da Atenção Básica para os ciclos de vida utilizando-se os critérios de eficácia, relevância e efetividade com dados secundários de 2012. A região Sul contém 31,57\% dos municípios satisfatórios enquanto a região Norte apresenta-se com 7,8\% de municípios nessa condição. Os resultados evidenciam as discrepâncias entre as regiões do País, apontando a necessidade de reestruturação desse nível de atenção nos municípios com piores desempenhos.

PALAVRAS-CHAVE Avaliação em saúde; Atenção Primária à Saúde; Gestão em saúde; Brasil.

ABSTRACT The aim was to evaluate the performance of Primary Care in Brazilian municipalities. We used the synthetic indicator proposed by the Evaluation Model of Primary Care - Nepas. We evaluated the size of the Provision of Primary Care for the life cycles using the criteria of efficacy, relevance, and effectiveness, using secondary data from 2012. The South contains $31.57 \%$ of satisfactory municipalities while the North is presented with $7.8 \%$ of municipalities in such condition. The results show discrepancies between the regions of the country, pointing out the need to restructure this level of attention in the municipalities with the worst performances.

KEYWORDS Health evaluation; Primary Health Care; Health management; Brazil. 


\section{Introdução}

A Atenção Básica ( $A B)$ à saúde no Brasil é considerada a porta de entrada preferencial para o usuário do Sistema Único de Saúde (SUS). A avaliação desse nível de atenção é estratégica para identificar as fragilidades persistentes que dificultam sua organização e operacionalização em direção à resolubilidade desejada para o serviço.

A necessidade de avaliação é também evidenciada pela escassez de recursos financeiros em vista do alto custo da atenção em saúde, recomendando racionalidade e eficiência na utilização dos investimentos para garantir serviços adequados às necessidades de saúde da população (TANAKA; MELO, 2000; BODSTEIN, 2002; FACCHINI ET AL., 2008).

O desempenho desigual dos serviços na $\mathrm{AB}$ decorre de questões demográficas, sociais e epidemiológicas observadas nos territórios, mas também pode ser associado às escolhas locais de prioridades para suprir a demanda de uma população. A descentralização político-administrativa, com ênfase na municipalização, fez com que o município assumisse a responsabilidade pela gestão do sistema de saúde em níveis de maior ou menor complexidade, com progressiva transferência de responsabilidades pela execução direta de ações e serviços de saúde (CASTRO; MACHADO, 2010; VIEIRA; GARNELO; HORTALE, 2010). Dadas as desigualdades de oferta, demanda e necessidade nos diversos municípios brasileiros, identificar pontos fracos e fortes no nível de atenção sob responsabilidade prioritária do gestor municipal pode constituir importante ferramenta de decisão local.

Em 2004, no estado de Santa Catarina, o Programa de Expansão e Consolidação da Saúde da Família (Proesf) orientou o fortalecimento da avaliação da $\mathrm{AB}$ por meio do desenvolvimento institucional de um modelo de avaliação para os municípios catarinenses. A parceria entre a Secretaria de Estado da Saúde de Santa Catarina e o Núcleo de Extensão e Pesquisa em Avaliação em Saúde
(Nepas) da Universidade Federal de Santa Catarina (UFSC) resultou na proposta de um indicador sintético para avaliar o desempenho da gestão da $\mathrm{AB}$ dos municípios catarinenses. A primeira aplicação desse modelo de avaliação aconteceu no ano de 2006, e desde então os municípios são avaliados bianualmente, com consequente classificação de desempenho segundo porte populacional (NICKEL ET AL., 2014).

O presente estudo teve por objetivo avaliar o desempenho de todos os municípios brasileiros quanto à dimensão de Provimento da Atenção Básica à Saúde.

\section{Metodologia}

Trata-se de uma pesquisa avaliativa, transversal, com abordagem quantitativa, sobre o desempenho do Provimento da Atenção Básica nos municípios brasileiros, utilizando-se um indicador sintético desenvolvido pelo Nepas da Universidade Federal de Santa Catarina (UFSC).

Esse indicador sintético é proveniente de um modelo de avaliação da gestão municipal da $A B$, constituído por uma matriz avaliativa dividida em duas dimensões: Gestão do Sistema Municipal de Saúde e Provimento da Atenção Básica à Saúde. Essas dimensões representam o dever do município de tornar igualitário e universal o acesso aos serviços de promoção, prevenção e recuperação da saúde e de reduzir o risco de doenças e de outros agravos. A metodologia completa com a matriz avaliativa, os rationales, a descrição das medidas e cálculos dos indicadores estão disponíveis na página eletrônica do Nepas (http://www.nepas.ufsc.br).

Para este estudo, foi selecionada a dimensão de Provimento da Atenção Básica à Saúde que avalia o desempenho da $\mathrm{AB}$ nos ciclos de vida (criança, adolescente, adulto e idoso), considerando-se ações de 'promoção e prevenção' e de 'diagnóstico e tratamento', utilizando-se os critérios 
de eficácia, efetividade e relevância. Neste estudo, os conceitos utilizados foram: a eficácia refere-se ao cumprimento das metas e protocolos estabelecidos; a efetividade reflete a capacidade em satisfazer as necessidades e expectativas de atenção à saúde - maximização dos resultados; e a relevância está em decisões que atendam expectativas da sociedade em relação ao Sistema Único de Saúde (SUS) - maximização do impacto (SCARATTI, 2007).
O universo da pesquisa foi composto pelos 5.565 municípios brasileiros e teve 2012 como ano de referência para a coleta dos dados.

$\mathrm{Na}$ matriz avaliativa original, a dimensão de Provimento da Atenção Básica é composta por 24 indicadores que utilizam dados primários e secundários. Pela viabilidade dessa pesquisa, foram utilizados os 21 indicadores com fonte de dados secundários (quadro 1).

Quadro 1. Indicadores utilizados na composição da dimensão Provimento da Atenção Básica à Saúde, de acordo com os ciclos de vida. Brasil, 2012

\begin{tabular}{|c|c|c|c|c|}
\hline \multirow{7}{*}{ 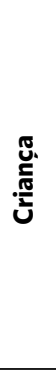 } & \multirow{5}{*}{ PP } & Critério & Indicador (Medida) & Fonte \\
\hline & & Relevância & Taxa de sobrevivência infantil no último triênio & $\mathrm{SIM} / \mathrm{IBGE}$ \\
\hline & & Efetividade & $\begin{array}{l}\text { Cobertura vacinal com a vacina tetravalente ou pentavalente em crianças menores de } 1 \\
\text { ano de idade. }\end{array}$ & $\mathrm{SI}-\mathrm{PNI} / \mathrm{IBGE}$ \\
\hline & & Eficácia & Nascidos vivos com $\mid G>=37$ semanas & Sinasc \\
\hline & & Relevância & Taxa de não internação hospitalar de crianças $<5$ anos no triênio & $\mathrm{SIH} / \mathrm{IBGE}$ \\
\hline & \multirow[t]{2}{*}{ DT } & Efetividade & Taxa de consultas de menores de 10 anos & $\mathrm{SIAB} / \mathrm{IBGE}$ \\
\hline & & Eficácia & Taxa de não internação em crianças $<5$ anos por diarreia & $\mathrm{SIH} / \mathrm{IBGE}$ \\
\hline \multirow{7}{*}{ 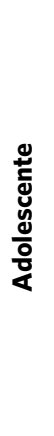 } & \multirow{5}{*}{ PP } & Critério & Indicador (Medida) & Fonte \\
\hline & & Relevância & Taxa de não mortalidade de adolescentes por causas externas no último triênio & $\mathrm{SIM} / \mathrm{IBGE}$ \\
\hline & & Efetividade & Taxa de adolescentes não grávidas no último triênio & Sinasc/IBGE \\
\hline & & Eficácia & $\begin{array}{l}\text { Percentual de gestantes adolescentes com } 7 \text { ou mais consultas de pré-natal no último } \\
\text { triênio }\end{array}$ & Sinasc \\
\hline & & Relevância & $\begin{array}{l}\text { Taxa de adolescentes acompanhados pelo Sistema de Vigilância Alimentar Nutricional } \\
\text { (Sisvan) no último ano }\end{array}$ & Sisvan \\
\hline & \multirow[t]{2}{*}{ DT } & Efetividade & Taxa de consultas de adolescentes na Atenção Básica & $\mathrm{SIAB} / \mathrm{IBGE}$ \\
\hline & & Eficácia & Taxa de primeira consulta odontológica para adolescentes & $\mathrm{SIA} / \mathrm{IBGE}$ \\
\hline \multirow{5}{*}{$\frac{\text { 을 }}{\frac{7}{2}}$} & \multirow{3}{*}{ PP } & Critério & Indicador (Medida) & Fonte \\
\hline & & Relevância & Sobrevivência Materna & $\mathrm{SIM} /$ Sinasc \\
\hline & & Eficácia & Acompanhamento pré-natal das gestantes adultas & Sinasc \\
\hline & \multirow{2}{*}{ DT } & Relevância & Taxa de não internação de adultos por doenças sensíveis à Atenção Básica & $\mathrm{SIH} / \mathrm{IBGE}$ \\
\hline & & Efetividade & Taxa de não internação por AVC ou ICC & $\mathrm{SIH} / \mathrm{IBGE}$ \\
\hline \multirow{6}{*}{ 옹 } & \multirow{4}{*}{$\mathbf{P P}$} & Critério & Indicador (Medida) & Fonte \\
\hline & & Relevância & Cobertura vacinal contra influenza em idosos & $\mathrm{SI}-\mathrm{PNI} / \mathrm{IBGE}$ \\
\hline & & Eficácia & Taxa de idosos não internados por fratura de colo do fêmur & $\mathrm{SIH} / \mathrm{IBGE}$ \\
\hline & & Relevância & Taxa de idosos não internados por doenças sensíveis à Atenção Básica & $\mathrm{SIH} / \mathrm{IBGE}$ \\
\hline & \multirow[t]{2}{*}{ DT } & Efetividade & Taxa de consulta de idosos & $\mathrm{SAI} / \mathrm{IBGE}$ \\
\hline & & Eficácia & Oferta de prótese dentária & PMA Complementar \\
\hline
\end{tabular}

Fonte: Matriz Avaliativa - Provimento da Atenção Básica. Nepas (2006).

Nota: PP - Promoção e Prevenção; DT - Diagnóstico e Tratamento. 
Nos indicadores 'Taxa de adultos não internados por doenças sensíveis à Atenção Básica' e 'Taxa de idosos não internados por doenças sensíveis à Atenção Básica', as doenças sensíveis à $A B$ são representadas pelas enfermidades diarreia e gastroenterite de origem infecciosa presumível, insuficiência cardíaca, pneumonia e asma (HENRIQUE; CALVO, 2009).

Quanto ao indicador 'Oferta de prótese', foi utilizada a variável 'Instalação de Prótese Dentária' do Sistema de Informação de Atenção Básica - PMA Complementar. Não há possibilidade de tabulação desse dado por faixa etária, e, por esse motivo, optou-se por dicotomizar o indicador, considerando-se a realização ou não desse procedimento, independentemente da quantidade registrada no sistema e da idade. A identificação de existência de registro desse procedimento no município estaria indicando a oferta do serviço, sendo os idosos os principais beneficiados.

A coleta de dados foi realizada nos diversos subsistemas do Departamento de Informática do Sistema Único de Saúde (Datasus), e foi utilizado o Microsoft Excel 2013 para a construção de planilha eletrônica de dados. Foi realizada a análise de consistência dos dados para detectar possíveis erros nas informações registradas nos bancos de dados.

Para efeito do cálculo dos indicadores, os municípios foram estratificados de acordo com o porte populacional, considerando-se o padrão de cobertura previsto na Estratégia Saúde da Família (ESF). Os 7 estratos foram divididos em: porte 1 com municípios de até 3.000 habitantes ( $\mathrm{n}=501$ ); porte 2 com municípios de 3.001 a 6.000 habitantes $(n=1123)$; porte $3 \mathrm{com}$ municípios de 6.001 a 10.000 habitantes
( $\mathrm{n}=884)$; porte 4 com municípios de 10.001 a 20.000 habitantes $(n=1388)$; porte $5 \mathrm{com}$ municípios de 20.001 a 50.000 habitantes $(\mathrm{n}=1055)$; porte $6 \mathrm{com}$ municípios de 50.001 a 100.000 habitantes $(n=326)$; e o porte 7 com municípios a partir de 100.001 habitantes $(n=288)$.

Após o cálculo dos indicadores, a próxima etapa consistiu na conversão desses valores no intervalo de 0 a 1, dentro de cada porte. $\mathrm{Na}$ distribuição de cada indicador, foram identificados os outliers (média +/- 3DP) para definir os valores mínimo e máximo, que passam a ser, respectivamente, 0 e 1. Com todos os indicadores tendo variação positiva, foi possível fazer a soma ponderada dos indicadores, por ciclo de vida, e do total de indicadores (indicador sintético), para avaliar o desempenho dos municípios. Ainda no conjunto de municípios de mesmo porte populacional, foi estabelecido o juízo de valor a partir da distribuição quartílica dos valores. Os municípios com valores abaixo ou igual ao primeiro quartil foram considerados insatisfatórios, os municípios com valores acima ou igual ao terceiro quartil foram considerados satisfatórios e aqueles com valores intermediários (entre o primeiro e o terceiro quartil) foram considerados regulares. Após essa classificação, os municípios foram reagrupados por estados e regiões para comparação do desempenho global e por ciclo de vida.

\section{Resultados}

Como pode ser observado nas tabelas $1 \mathrm{e}$ 2, os 5.565 municípios brasileiros foram avaliados de acordo com os ciclos de vida (criança, adolescente, adulto e idoso) por meio do indicador sintético proposto pelo Nepas. 
Tabela 1. Distribuição do número de municípios de acordo com o juízo de valor do desempenho do Provimento da Atenção Básica, dos ciclos de vida da criança e do adolescente. Brasil, 2012

\begin{tabular}{|c|c|c|c|c|c|c|c|c|}
\hline \multirow[b]{2}{*}{ Regiões (UF) } & \multirow{2}{*}{$\begin{array}{r}\text { CRIANÇA } \\
\text { S } \\
n \\
(\%)\end{array}$} & \multicolumn{7}{|c|}{ ADOLESCENTE } \\
\hline & & $\begin{array}{r}\mathrm{R} \\
\mathrm{n} \\
(\%) \\
\end{array}$ & $\begin{array}{r}\text { I } \\
\text { n } \\
(\%)\end{array}$ & $\begin{array}{r}\text { Total } \\
\mathbf{n} \\
(\%)\end{array}$ & $\begin{array}{r}\mathrm{S} \\
\mathrm{n} \\
(\%)\end{array}$ & $\begin{array}{r}\mathbf{R} \\
n \\
(\%)\end{array}$ & $\begin{array}{r}\text { I } \\
\text { n } \\
(\%)\end{array}$ & $\begin{array}{r}\text { Total } \\
n \\
(\%)\end{array}$ \\
\hline SUL & $\begin{array}{r}375 \\
(31,56)\end{array}$ & $\begin{array}{r}595 \\
(50,08)\end{array}$ & $\begin{array}{r}218 \\
(18,36)\end{array}$ & $\begin{array}{r}1188 \\
(100,00)\end{array}$ & $\begin{array}{r}420 \\
(35,35)\end{array}$ & $\begin{array}{r}631 \\
(53,11)\end{array}$ & $\begin{array}{r}137 \\
(11,53)\end{array}$ & $\begin{array}{r}1188 \\
(100,00)\end{array}$ \\
\hline Santa Catarina & $\begin{array}{r}124 \\
(42,32)\end{array}$ & $\begin{array}{r}150 \\
(51,20)\end{array}$ & $\begin{array}{r}19 \\
(6,48)\end{array}$ & $\begin{array}{r}293 \\
(100,00)\end{array}$ & $\begin{array}{r}115 \\
(39,25)\end{array}$ & $\begin{array}{r}152 \\
(51,88)\end{array}$ & $\begin{array}{r}26 \\
(8,87)\end{array}$ & $\begin{array}{r}293 \\
(100,00)\end{array}$ \\
\hline Paraná & $\begin{array}{r}139 \\
(34,84)\end{array}$ & $\begin{array}{r}184 \\
(46,11)\end{array}$ & $\begin{array}{r}76 \\
(19,05)\end{array}$ & $\begin{array}{r}399 \\
(100,00)\end{array}$ & $\begin{array}{r}126 \\
(31,58)\end{array}$ & $\begin{array}{r}210 \\
(52,63)\end{array}$ & $\begin{array}{r}63 \\
(15,79)\end{array}$ & $\begin{array}{r}399 \\
(100,00)\end{array}$ \\
\hline Rio Grande do Sul & $\begin{array}{r}112 \\
(22,58) \\
\end{array}$ & $\begin{array}{r}261 \\
(52,62) \\
\end{array}$ & $\begin{array}{r}123 \\
(24,80) \\
\end{array}$ & $\begin{array}{r}496 \\
(100,00) \\
\end{array}$ & $\begin{array}{r}179 \\
(36,09) \\
\end{array}$ & $\begin{array}{r}269 \\
(54,23) \\
\end{array}$ & $\begin{array}{r}48 \\
(9,68) \\
\end{array}$ & $\begin{array}{r}496 \\
(100,00) \\
\end{array}$ \\
\hline SUDESTE & $\begin{array}{r}498 \\
(29,86)\end{array}$ & $\begin{array}{r}876 \\
(52,52)\end{array}$ & $\begin{array}{r}294 \\
(17,62)\end{array}$ & $\begin{array}{r}1668 \\
(100,00)\end{array}$ & $\begin{array}{r}659 \\
(39,51)\end{array}$ & $\begin{array}{r}844 \\
(50,60)\end{array}$ & $\begin{array}{r}165 \\
(9,89)\end{array}$ & $\begin{array}{r}1668 \\
(100,00)\end{array}$ \\
\hline Espírito Santo & $\begin{array}{r}24 \\
(30,77)\end{array}$ & $\begin{array}{r}33 \\
(42,31)\end{array}$ & $\begin{array}{r}21 \\
(26,92)\end{array}$ & $\begin{array}{r}78 \\
(100,00)\end{array}$ & $\begin{array}{r}16 \\
(20,51)\end{array}$ & $\begin{array}{r}44 \\
(56,41)\end{array}$ & $\begin{array}{r}18 \\
(23,08)\end{array}$ & $\begin{array}{r}78 \\
(100,00)\end{array}$ \\
\hline São Paulo & $\begin{array}{r}204 \\
(31,63)\end{array}$ & $\begin{array}{r}344 \\
(53,33)\end{array}$ & $\begin{array}{r}97 \\
(15,04)\end{array}$ & $\begin{array}{r}645 \\
(100,00)\end{array}$ & $\begin{array}{r}217 \\
(33,64)\end{array}$ & $\begin{array}{r}373 \\
(57,83)\end{array}$ & $\begin{array}{r}55 \\
(8,53)\end{array}$ & $\begin{array}{r}645 \\
(100,00)\end{array}$ \\
\hline Minas Gerais & $\begin{array}{r}237 \\
(27,78)\end{array}$ & $\begin{array}{r}456 \\
(53,46)\end{array}$ & $\begin{array}{r}160 \\
(18,76)\end{array}$ & $\begin{array}{r}853 \\
(100,00)\end{array}$ & $\begin{array}{r}399 \\
(46,78)\end{array}$ & $\begin{array}{r}380 \\
(44,55)\end{array}$ & $\begin{array}{r}74 \\
(8,68)\end{array}$ & $\begin{array}{r}853 \\
(100,00)\end{array}$ \\
\hline Rio de Janeiro & $\begin{array}{r}33 \\
(35,87) \\
\end{array}$ & $\begin{array}{r}43 \\
(46,74) \\
\end{array}$ & $\begin{array}{r}16 \\
(17,39) \\
\end{array}$ & $\begin{array}{r}92 \\
(100,00) \\
\end{array}$ & $\begin{array}{r}27 \\
(29,35) \\
\end{array}$ & $\begin{array}{r}47 \\
(51,09) \\
\end{array}$ & $\begin{array}{r}18 \\
(19,57) \\
\end{array}$ & $\begin{array}{r}92 \\
(100,00) \\
\end{array}$ \\
\hline NORTE & $\begin{array}{r}45 \\
(10,02)\end{array}$ & $\begin{array}{r}215 \\
(47,89)\end{array}$ & $\begin{array}{r}189 \\
(42,09)\end{array}$ & $\begin{array}{r}449 \\
(100,00)\end{array}$ & $\begin{array}{r}22 \\
(4,90)\end{array}$ & $\begin{array}{r}118 \\
(26,28)\end{array}$ & $\begin{array}{r}309 \\
(68,82)\end{array}$ & $\begin{array}{r}449 \\
(100,00)\end{array}$ \\
\hline Acre & $\begin{array}{r}2 \\
(9,10)\end{array}$ & $\begin{array}{r}10 \\
(45,45)\end{array}$ & $\begin{array}{r}10 \\
(45,45)\end{array}$ & $\begin{array}{r}22 \\
(100,00)\end{array}$ & $\begin{array}{r}0 \\
(0,00)\end{array}$ & $\begin{array}{r}4 \\
(18,18)\end{array}$ & $\begin{array}{r}18 \\
(81,82)\end{array}$ & $\begin{array}{r}22 \\
(100,00)\end{array}$ \\
\hline Amapá & $\begin{array}{r}1 \\
(6,25)\end{array}$ & $\begin{array}{r}8 \\
(50,00)\end{array}$ & $\begin{array}{r}7 \\
(43,75)\end{array}$ & $\begin{array}{r}16 \\
(100,00)\end{array}$ & $\begin{array}{r}0 \\
(0,00)\end{array}$ & $\begin{array}{r}0 \\
(0,00)\end{array}$ & $\begin{array}{r}16 \\
(100,00)\end{array}$ & $\begin{array}{r}16 \\
(100,00)\end{array}$ \\
\hline Amazonas & $\begin{array}{r}11 \\
(17,74)\end{array}$ & $\begin{array}{r}39 \\
(62,90)\end{array}$ & $\begin{array}{r}12 \\
(19,36)\end{array}$ & $\begin{array}{r}62 \\
(100,00)\end{array}$ & $\begin{array}{r}0 \\
(0,00)\end{array}$ & $\begin{array}{r}20 \\
(32,26)\end{array}$ & $\begin{array}{r}42 \\
(67,74)\end{array}$ & $\begin{array}{r}62 \\
(100,00)\end{array}$ \\
\hline Pará & $\begin{array}{r}6 \\
(4,20)\end{array}$ & $\begin{array}{r}62 \\
(43,36)\end{array}$ & $\begin{array}{r}75 \\
(52,44)\end{array}$ & $\begin{array}{r}143 \\
(100,00)\end{array}$ & $\begin{array}{r}2 \\
(1,40)\end{array}$ & $\begin{array}{r}25 \\
(17,48)\end{array}$ & $\begin{array}{r}116 \\
(81,12)\end{array}$ & $\begin{array}{r}143 \\
(100,00)\end{array}$ \\
\hline Rondônia & $\begin{array}{r}7 \\
(13,46)\end{array}$ & $\begin{array}{r}23 \\
(44,23)\end{array}$ & $\begin{array}{r}22 \\
(42,31)\end{array}$ & $\begin{array}{r}52 \\
(100,00)\end{array}$ & $\begin{array}{r}5 \\
(9,62)\end{array}$ & $\begin{array}{r}24 \\
(46,15)\end{array}$ & $\begin{array}{r}23 \\
(44,23)\end{array}$ & $\begin{array}{r}52 \\
(100,00)\end{array}$ \\
\hline Roraima & $\begin{array}{r}0 \\
(0,00)\end{array}$ & $\begin{array}{r}3 \\
(20,00)\end{array}$ & $\begin{array}{r}12 \\
(80,00)\end{array}$ & $\begin{array}{r}15 \\
(100,00)\end{array}$ & $\begin{array}{r}0 \\
(0,00)\end{array}$ & $\begin{array}{r}2 \\
(13,33)\end{array}$ & $\begin{array}{r}13 \\
(86,67)\end{array}$ & $\begin{array}{r}15 \\
(100,00)\end{array}$ \\
\hline Tocantins & $\begin{array}{r}18 \\
(12,95) \\
\end{array}$ & $\begin{array}{r}70 \\
(50,36) \\
\end{array}$ & $\begin{array}{r}51 \\
(63,31) \\
\end{array}$ & $\begin{array}{r}139 \\
(100,00) \\
\end{array}$ & $\begin{array}{r}15 \\
(10,79) \\
\end{array}$ & $\begin{array}{r}43 \\
(30,94) \\
\end{array}$ & $\begin{array}{r}81 \\
(58,27) \\
\end{array}$ & $\begin{array}{r}139 \\
(100,00) \\
\end{array}$ \\
\hline NORDESTE & $\begin{array}{r}347 \\
(19,34)\end{array}$ & $\begin{array}{r}862 \\
(48,05)\end{array}$ & $\begin{array}{r}585 \\
(32,61)\end{array}$ & $\begin{array}{r}1794 \\
(100,00)\end{array}$ & $\begin{array}{r}202 \\
(11,26)\end{array}$ & $\begin{array}{r}919 \\
(51,23)\end{array}$ & $\begin{array}{r}673 \\
(37,51)\end{array}$ & $\begin{array}{r}1794 \\
(100,00)\end{array}$ \\
\hline Alagoas & $\begin{array}{r}1 \\
(0,99)\end{array}$ & $\begin{array}{r}46 \\
(45,10)\end{array}$ & $\begin{array}{r}55 \\
(53,91)\end{array}$ & $\begin{array}{r}102 \\
(100,00)\end{array}$ & $\begin{array}{r}5 \\
(4,90)\end{array}$ & $\begin{array}{r}31 \\
(30,39)\end{array}$ & $\begin{array}{r}66 \\
(64,71)\end{array}$ & $\begin{array}{r}102 \\
(100,00)\end{array}$ \\
\hline Bahia & $\begin{array}{r}48 \\
(11,51)\end{array}$ & $\begin{array}{r}163 \\
(39,10)\end{array}$ & $\begin{array}{r}206 \\
(49,39)\end{array}$ & $\begin{array}{r}417 \\
(100,00)\end{array}$ & $\begin{array}{r}37 \\
(8,87)\end{array}$ & $\begin{array}{r}198 \\
(47,48)\end{array}$ & $\begin{array}{r}182 \\
(43,65)\end{array}$ & $\begin{array}{r}417 \\
(100,00)\end{array}$ \\
\hline Ceará & $\begin{array}{r}68 \\
(36,96) \\
\end{array}$ & $\begin{array}{r}96 \\
(52,18) \\
\end{array}$ & $\begin{array}{r}20 \\
(10,86) \\
\end{array}$ & $\begin{array}{r}184 \\
(100,00) \\
\end{array}$ & $\begin{array}{r}52 \\
(28,26) \\
\end{array}$ & $\begin{array}{r}112 \\
(60,87) \\
\end{array}$ & $\begin{array}{r}20 \\
(10,87) \\
\end{array}$ & $\begin{array}{r}184 \\
(100,00) \\
\end{array}$ \\
\hline Maranhão & $\begin{array}{r}35 \\
(16,13)\end{array}$ & $\begin{array}{r}107 \\
(49,31)\end{array}$ & $\begin{array}{r}75 \\
(34,56)\end{array}$ & $\begin{array}{r}217 \\
(100,00)\end{array}$ & $\begin{array}{r}18 \\
(8,29)\end{array}$ & $\begin{array}{r}88 \\
(40,55)\end{array}$ & $\begin{array}{r}111 \\
(51,15)\end{array}$ & $\begin{array}{r}217 \\
(100,00)\end{array}$ \\
\hline
\end{tabular}




\begin{tabular}{|c|c|c|c|c|c|c|c|c|}
\hline \multicolumn{9}{|l|}{ Tabela 1. (cont.) } \\
\hline Paraíba & $\begin{array}{r}50 \\
(22,42)\end{array}$ & $\begin{array}{r}125 \\
(56,05)\end{array}$ & $\begin{array}{r}48 \\
(21,53)\end{array}$ & $\begin{array}{r}223 \\
(100,00)\end{array}$ & $\begin{array}{r}39 \\
(17,49)\end{array}$ & $\begin{array}{r}147 \\
(65,92\end{array}$ & $\begin{array}{r}37 \\
(16,59)\end{array}$ & $\begin{array}{r}223 \\
(100,00)\end{array}$ \\
\hline Piauí & $\begin{array}{r}39 \\
(17,41)\end{array}$ & $\begin{array}{r}111 \\
(49,55)\end{array}$ & $\begin{array}{r}74 \\
(33,04)\end{array}$ & $\begin{array}{r}224 \\
(100,00)\end{array}$ & $\begin{array}{r}14 \\
(6,25)\end{array}$ & $\begin{array}{r}100 \\
(44,64)\end{array}$ & $\begin{array}{r}110 \\
(49,11)\end{array}$ & $\begin{array}{r}224 \\
(100,00)\end{array}$ \\
\hline Pernambuco & $\begin{array}{r}22 \\
(11,90)\end{array}$ & $\begin{array}{r}98 \\
(52,98)\end{array}$ & $\begin{array}{r}65 \\
(35,12)\end{array}$ & $\begin{array}{r}185 \\
(100,00)\end{array}$ & $\begin{array}{r}8 \\
(4,32)\end{array}$ & $\begin{array}{r}117 \\
(63,24)\end{array}$ & $\begin{array}{r}60 \\
(32,43)\end{array}$ & $\begin{array}{r}185 \\
(100,00)\end{array}$ \\
\hline Rio Grande do Norte & $\begin{array}{r}50 \\
(29,94)\end{array}$ & $\begin{array}{r}79 \\
(47,30)\end{array}$ & $\begin{array}{r}38 \\
(22,76)\end{array}$ & $\begin{array}{r}167 \\
(100,00)\end{array}$ & $\begin{array}{r}27 \\
(16,17)\end{array}$ & $\begin{array}{r}96 \\
(57,49)\end{array}$ & $\begin{array}{r}44 \\
(26,35)\end{array}$ & $\begin{array}{r}167 \\
(100,00)\end{array}$ \\
\hline Sergipe & $\begin{array}{r}34 \\
(45,33) \\
\end{array}$ & $\begin{array}{r}37 \\
(49,33) \\
\end{array}$ & $\begin{array}{r}4 \\
(5,34) \\
\end{array}$ & $\begin{array}{r}75 \\
(100,00) \\
\end{array}$ & $\begin{array}{r}2 \\
(2,67) \\
\end{array}$ & $\begin{array}{r}30 \\
(40,00) \\
\end{array}$ & $\begin{array}{r}43 \\
(57,33) \\
\end{array}$ & $\begin{array}{r}75 \\
(100,00) \\
\end{array}$ \\
\hline CENTRO-OESTE & $\begin{array}{r}128 \\
(27,48)\end{array}$ & $\begin{array}{r}235 \\
(50,43)\end{array}$ & $\begin{array}{r}103 \\
(22,09)\end{array}$ & $\begin{array}{r}466 \\
(100,00)\end{array}$ & $\begin{array}{r}96 \\
(20,60)\end{array}$ & $\begin{array}{r}253 \\
(54,29)\end{array}$ & $\begin{array}{r}117 \\
(25,11)\end{array}$ & $\begin{array}{r}466 \\
(100,00)\end{array}$ \\
\hline Goiás & $\begin{array}{r}54 \\
(21,95)\end{array}$ & $\begin{array}{r}133 \\
(54,06)\end{array}$ & $\begin{array}{r}59 \\
(23,99)\end{array}$ & $\begin{array}{r}246 \\
(100,00)\end{array}$ & $\begin{array}{r}57 \\
(23,17)\end{array}$ & $\begin{array}{r}136 \\
(55,28)\end{array}$ & $\begin{array}{r}53 \\
(21,54)\end{array}$ & $\begin{array}{r}246 \\
(100,00)\end{array}$ \\
\hline Mato Grosso & $\begin{array}{r}54 \\
(38,30)\end{array}$ & $\begin{array}{r}58 \\
(41,13)\end{array}$ & $\begin{array}{r}29 \\
(20,57)\end{array}$ & $\begin{array}{r}141 \\
(100,00)\end{array}$ & $\begin{array}{r}29 \\
(20,57)\end{array}$ & $\begin{array}{r}80 \\
(56,74)\end{array}$ & $\begin{array}{r}32 \\
(22,70)\end{array}$ & $\begin{array}{r}141 \\
(100,00)\end{array}$ \\
\hline Mato Grosso do Sul & $\begin{array}{r}20 \\
(25,64)\end{array}$ & $\begin{array}{r}43 \\
(55,13)\end{array}$ & $\begin{array}{r}15 \\
(19,23)\end{array}$ & $\begin{array}{r}78 \\
(100,00)\end{array}$ & $\begin{array}{r}10 \\
(12,82)\end{array}$ & $\begin{array}{r}36 \\
(46,15)\end{array}$ & $\begin{array}{r}32 \\
(41,03)\end{array}$ & $\begin{array}{r}78 \\
(100,00)\end{array}$ \\
\hline Distrito Federal & $\begin{array}{r}0 \\
(0,00) \\
\end{array}$ & $\begin{array}{r}1 \\
(100,00) \\
\end{array}$ & $\begin{array}{r}0 \\
(0,00) \\
\end{array}$ & $\begin{array}{r}1 \\
(100,00) \\
\end{array}$ & $\begin{array}{r}0 \\
(0,00) \\
\end{array}$ & $\begin{array}{r}1 \\
(100,00) \\
\end{array}$ & $\begin{array}{r}0 \\
(0,00) \\
\end{array}$ & $(100,00)$ \\
\hline TOTAL & $\begin{array}{r}1393 \\
(25,03)\end{array}$ & $\begin{array}{r}2783 \\
(50,01)\end{array}$ & $\begin{array}{r}1389 \\
(24,96)\end{array}$ & $\begin{array}{r}5565 \\
(100,00)\end{array}$ & $\begin{array}{r}1399 \\
(25,14)\end{array}$ & $\begin{array}{r}2765 \\
(49,69)\end{array}$ & $\begin{array}{r}1401 \\
(25,18)\end{array}$ & $\begin{array}{r}5565 \\
(100,00)\end{array}$ \\
\hline
\end{tabular}

Fonte: laboração própria.

Nota: S - Satisfatório; R - Regular; I - Insatisfatório.

Tabela 2. Distribuição do número de municípios de acordo com o juízo de valor do desempenho do Provimento da Atenção Básica, dos ciclos de vida do adulto e do idoso. Brasil, 2012

\begin{tabular}{|c|c|c|c|c|c|c|c|c|}
\hline \multirow[b]{2}{*}{ Regiões (UF) } & \multicolumn{7}{|c|}{ ADULTO } & \multirow{2}{*}{$\begin{array}{r}\text { IDOSO } \\
\text { Total } \\
n \\
(\%)\end{array}$} \\
\hline & $\begin{array}{r}\mathrm{S} \\
\mathrm{n} \\
(\%)\end{array}$ & $\begin{array}{r}R \\
n \\
(\%)\end{array}$ & $\begin{array}{r} \\
\mathrm{n} \\
(\%)\end{array}$ & $\begin{array}{r}\text { Total } \\
\mathbf{n} \\
(\%)\end{array}$ & $\begin{array}{r}\mathrm{S} \\
\mathrm{n} \\
(\%)\end{array}$ & $\begin{array}{r}R \\
n \\
(\%)\end{array}$ & $\begin{array}{r}\text { I } \\
\text { n } \\
(\%)\end{array}$ & \\
\hline SUL & $\begin{array}{r}384 \\
(32,32)\end{array}$ & $\begin{array}{r}532 \\
(44,78)\end{array}$ & $\begin{array}{r}272 \\
(22,90)\end{array}$ & $\begin{array}{r}1188 \\
(100,00)\end{array}$ & $\begin{array}{r}228 \\
(19,19)\end{array}$ & $\begin{array}{r}594 \\
(50,00)\end{array}$ & $\begin{array}{r}366 \\
(30,81)\end{array}$ & $\begin{array}{r}1188 \\
(100,00)\end{array}$ \\
\hline Santa Catarina & $\begin{array}{r}88 \\
(30,03)\end{array}$ & $\begin{array}{r}135 \\
(46,08)\end{array}$ & $\begin{array}{r}70 \\
(23,89)\end{array}$ & $\begin{array}{r}293 \\
(100,00)\end{array}$ & $\begin{array}{r}73 \\
(24,91)\end{array}$ & $\begin{array}{r}154 \\
(52,56)\end{array}$ & $\begin{array}{r}66 \\
(22,53)\end{array}$ & $\begin{array}{r}293 \\
(100,00)\end{array}$ \\
\hline Paraná & $\begin{array}{r}98 \\
(24,56)\end{array}$ & $\begin{array}{r}171 \\
(42,86)\end{array}$ & $\begin{array}{r}130 \\
(32,58)\end{array}$ & $\begin{array}{r}399 \\
(100,00)\end{array}$ & $\begin{array}{r}81 \\
(20,30)\end{array}$ & $\begin{array}{r}177 \\
(44,36)\end{array}$ & $\begin{array}{r}141 \\
(35,34)\end{array}$ & $\begin{array}{r}399 \\
(100,00)\end{array}$ \\
\hline Rio Grande do Sul & $\begin{array}{r}198 \\
(39,92)\end{array}$ & $\begin{array}{r}226 \\
(45,56)\end{array}$ & $\begin{array}{r}72 \\
(14,52)\end{array}$ & $\begin{array}{r}496 \\
(100,00)\end{array}$ & $\begin{array}{r}74 \\
(14,92)\end{array}$ & $\begin{array}{r}263 \\
(53,02)\end{array}$ & $\begin{array}{r}159 \\
(32,06)\end{array}$ & $\begin{array}{r}496 \\
(100,00)\end{array}$ \\
\hline SUDESTE & $\begin{array}{r}589 \\
(35,31)\end{array}$ & $\begin{array}{r}791 \\
(47,42)\end{array}$ & $\begin{array}{r}288 \\
(17,27)\end{array}$ & $\begin{array}{r}1668 \\
(100,00)\end{array}$ & $\begin{array}{r}277 \\
(16,61)\end{array}$ & $\begin{array}{r}760 \\
(45,56)\end{array}$ & $\begin{array}{r}631 \\
(37,83)\end{array}$ & $\begin{array}{r}1668 \\
(100,00)\end{array}$ \\
\hline Espírito Santo & $\begin{array}{r}26 \\
(33,33)\end{array}$ & $\begin{array}{r}37 \\
(47,44)\end{array}$ & $\begin{array}{r}15 \\
(19,23)\end{array}$ & $\begin{array}{r}78 \\
(100,00)\end{array}$ & $\begin{array}{r}15 \\
(19,23)\end{array}$ & $\begin{array}{r}39 \\
(50,00)\end{array}$ & $\begin{array}{r}24 \\
(30,77)\end{array}$ & $\begin{array}{r}78 \\
(100,00)\end{array}$ \\
\hline São Paulo & $\begin{array}{r}314 \\
(48,68)\end{array}$ & $\begin{array}{r}286 \\
(44,34)\end{array}$ & $\begin{array}{r}45 \\
(6,98)\end{array}$ & $\begin{array}{r}645 \\
(100,00)\end{array}$ & $\begin{array}{r}88 \\
(13,64)\end{array}$ & $\begin{array}{r}255 \\
(39,53)\end{array}$ & $\begin{array}{r}302 \\
(46,82)\end{array}$ & $\begin{array}{r}645 \\
(100,00)\end{array}$ \\
\hline Minas Gerais & $\begin{array}{r}232 \\
(27,20)\end{array}$ & $\begin{array}{r}431 \\
(50,53)\end{array}$ & $\begin{array}{r}190 \\
(22,27)\end{array}$ & $\begin{array}{r}853 \\
(100,00)\end{array}$ & $\begin{array}{r}150 \\
(17,58)\end{array}$ & $\begin{array}{r}418 \\
(49,00)\end{array}$ & $\begin{array}{r}285 \\
(33,41)\end{array}$ & $\begin{array}{r}853 \\
(100,00)\end{array}$ \\
\hline
\end{tabular}




\begin{tabular}{|c|c|c|c|c|c|c|c|c|}
\hline \multicolumn{9}{|l|}{ Tabela 2. (cont.) } \\
\hline Rio de Janeiro & $\begin{array}{r}17 \\
(18,48)\end{array}$ & $\begin{array}{r}37 \\
(40,22)\end{array}$ & $\begin{array}{r}38 \\
(41,30)\end{array}$ & $\begin{array}{r}92 \\
(100,00)\end{array}$ & $\begin{array}{r}24 \\
(26,09)\end{array}$ & $\begin{array}{r}48 \\
(52,17)\end{array}$ & $\begin{array}{r}20 \\
(21,74)\end{array}$ & $\begin{array}{r}92 \\
(100,00)\end{array}$ \\
\hline NORTE & $\begin{array}{r}18 \\
(4,01)\end{array}$ & $\begin{array}{r}270 \\
(60,13)\end{array}$ & $\begin{array}{r}161 \\
(35,86)\end{array}$ & $\begin{array}{r}449 \\
(100,00)\end{array}$ & $\begin{array}{r}129 \\
(28,73)\end{array}$ & $\begin{array}{r}269 \\
(59,91)\end{array}$ & $\begin{array}{r}51 \\
(11,36)\end{array}$ & $\begin{array}{r}449 \\
(100,00)\end{array}$ \\
\hline Acre & $\begin{array}{r}0 \\
(0,00)\end{array}$ & $\begin{array}{r}19 \\
(86,36)\end{array}$ & $\begin{array}{r}3 \\
(13,64)\end{array}$ & $\begin{array}{r}22 \\
(100,00)\end{array}$ & $\begin{array}{r}5 \\
(22,73)\end{array}$ & $\begin{array}{r}15 \\
(68,18)\end{array}$ & $\begin{array}{r}2 \\
(9,09)\end{array}$ & $\begin{array}{r}22 \\
(100,00)\end{array}$ \\
\hline Amapá & $\begin{array}{r}0 \\
(0,00)\end{array}$ & $\begin{array}{r}13 \\
(81,25)\end{array}$ & $\begin{array}{r}3 \\
(18,75)\end{array}$ & $\begin{array}{r}16 \\
(100,00)\end{array}$ & $\begin{array}{r}9 \\
(56,25)\end{array}$ & $\begin{array}{r}6 \\
(37,50)\end{array}$ & $\begin{array}{r}1 \\
(6,25)\end{array}$ & $\begin{array}{r}16 \\
(100,00)\end{array}$ \\
\hline Amazonas & $\begin{array}{r}6 \\
(9,68)\end{array}$ & $\begin{array}{r}41 \\
(66,13)\end{array}$ & $\begin{array}{r}15 \\
(24,19)\end{array}$ & $\begin{array}{r}62 \\
(100,00)\end{array}$ & $\begin{array}{r}38 \\
(61,29)\end{array}$ & $\begin{array}{r}24 \\
(38,71)\end{array}$ & $\begin{array}{r}0 \\
(0,00)\end{array}$ & $\begin{array}{r}62 \\
(100,00)\end{array}$ \\
\hline Pará & $\begin{array}{r}2 \\
(1,40)\end{array}$ & $\begin{array}{r}77 \\
(53,85)\end{array}$ & $\begin{array}{r}64 \\
(44,76)\end{array}$ & $\begin{array}{r}143 \\
(100,00)\end{array}$ & $\begin{array}{r}38 \\
(26,57)\end{array}$ & $\begin{array}{r}88 \\
(61,54)\end{array}$ & $\begin{array}{r}17 \\
(11,89)\end{array}$ & $\begin{array}{r}143 \\
(100,00)\end{array}$ \\
\hline Rondônia & $\begin{array}{r}5 \\
(9,62)\end{array}$ & $\begin{array}{r}36 \\
(69,23)\end{array}$ & $\begin{array}{r}11 \\
(21,15)\end{array}$ & $\begin{array}{r}52 \\
(100,00)\end{array}$ & $\begin{array}{r}11 \\
(21,15)\end{array}$ & $\begin{array}{r}30 \\
(57,69)\end{array}$ & $\begin{array}{r}11 \\
(21,15)\end{array}$ & $\begin{array}{r}52 \\
(100,00)\end{array}$ \\
\hline Roraima & $\begin{array}{r}0 \\
(0,00)\end{array}$ & $\begin{array}{r}12 \\
(80,00)\end{array}$ & $\begin{array}{r}3 \\
(20,00)\end{array}$ & $\begin{array}{r}15 \\
(100,00)\end{array}$ & $\begin{array}{r}0 \\
(0,00)\end{array}$ & $\begin{array}{r}14 \\
(93,33)\end{array}$ & $\begin{array}{r}1 \\
(6,67)\end{array}$ & $\begin{array}{r}15 \\
(100,00)\end{array}$ \\
\hline Tocantins & $\begin{array}{r}5 \\
(3,60) \\
\end{array}$ & $\begin{array}{r}72 \\
(51,80) \\
\end{array}$ & $\begin{array}{r}62 \\
(44,60) \\
\end{array}$ & $\begin{array}{r}139 \\
(100,00) \\
\end{array}$ & $\begin{array}{r}28 \\
(20,14) \\
\end{array}$ & $\begin{array}{r}92 \\
(66,19) \\
\end{array}$ & $\begin{array}{r}19 \\
(13,67) \\
\end{array}$ & $\begin{array}{r}139 \\
(100,00) \\
\end{array}$ \\
\hline NORDESTE & $\begin{array}{r}277 \\
(15,44)\end{array}$ & $\begin{array}{r}918 \\
(51,17)\end{array}$ & $\begin{array}{r}599 \\
(33,39)\end{array}$ & $\begin{array}{r}1794 \\
(100,00)\end{array}$ & $\begin{array}{r}643 \\
(35,84)\end{array}$ & $\begin{array}{r}1007 \\
(56,13)\end{array}$ & $\begin{array}{r}144 \\
(8,03)\end{array}$ & $\begin{array}{r}1794 \\
(100,00)\end{array}$ \\
\hline Alagoas & $\begin{array}{r}2 \\
(1,96)\end{array}$ & $\begin{array}{r}73 \\
(71,57)\end{array}$ & $\begin{array}{r}27 \\
(26,47)\end{array}$ & $\begin{array}{r}102 \\
(100,00)\end{array}$ & $\begin{array}{r}34 \\
(33,33)\end{array}$ & $\begin{array}{r}65 \\
(63,73)\end{array}$ & $\begin{array}{r}3 \\
(2,94)\end{array}$ & $\begin{array}{r}102 \\
(100,00)\end{array}$ \\
\hline Bahia & $\begin{array}{r}30 \\
(7,19)\end{array}$ & $\begin{array}{r}185 \\
(44,36)\end{array}$ & $\begin{array}{r}202 \\
(48,44)\end{array}$ & $\begin{array}{r}417 \\
(100,00)\end{array}$ & $\begin{array}{r}97 \\
(23,26)\end{array}$ & $\begin{array}{r}249 \\
(59,71)\end{array}$ & $\begin{array}{r}71 \\
(17,03)\end{array}$ & $\begin{array}{r}417 \\
(100,00)\end{array}$ \\
\hline Ceará & $\begin{array}{r}69 \\
(37,50)\end{array}$ & $\begin{array}{r}97 \\
(52,72)\end{array}$ & $\begin{array}{r}18 \\
(9,78)\end{array}$ & $\begin{array}{r}184 \\
(100,00)\end{array}$ & $\begin{array}{r}105 \\
(57,07)\end{array}$ & $\begin{array}{r}77 \\
(41,85)\end{array}$ & $\begin{array}{r}2 \\
(1,09)\end{array}$ & $\begin{array}{r}184 \\
(100,00)\end{array}$ \\
\hline Maranhão & $\begin{array}{r}5 \\
(2,30)\end{array}$ & $\begin{array}{r}85 \\
(39,17)\end{array}$ & $\begin{array}{r}127 \\
(58,53)\end{array}$ & $\begin{array}{r}217 \\
(100,00)\end{array}$ & $\begin{array}{r}81 \\
(37,33)\end{array}$ & $\begin{array}{r}122 \\
(56,22)\end{array}$ & $\begin{array}{r}14 \\
(6,45)\end{array}$ & $\begin{array}{r}217 \\
(100,00)\end{array}$ \\
\hline Paraíba & $\begin{array}{r}53 \\
(23,77)\end{array}$ & $\begin{array}{r}128 \\
(57,40)\end{array}$ & $\begin{array}{r}42 \\
(18,83)\end{array}$ & $\begin{array}{r}223 \\
(100,00)\end{array}$ & $\begin{array}{r}94 \\
(42,15)\end{array}$ & $\begin{array}{r}119 \\
(53,36)\end{array}$ & $\begin{array}{r}10 \\
(4,48)\end{array}$ & $\begin{array}{r}223 \\
(100,00)\end{array}$ \\
\hline Piauí & $\begin{array}{r}6 \\
(2,68)\end{array}$ & $\begin{array}{r}97 \\
(43,30)\end{array}$ & $\begin{array}{r}121 \\
(54,02)\end{array}$ & $\begin{array}{r}224 \\
(100,00)\end{array}$ & $\begin{array}{r}80 \\
(35,71)\end{array}$ & $\begin{array}{r}121 \\
(54,02)\end{array}$ & $\begin{array}{r}23 \\
(10,27)\end{array}$ & $\begin{array}{r}224 \\
(100,00)\end{array}$ \\
\hline Pernambuco & $\begin{array}{r}53 \\
(28,65)\end{array}$ & $\begin{array}{r}106 \\
(57,30)\end{array}$ & $\begin{array}{r}26 \\
(14,05)\end{array}$ & $\begin{array}{r}185 \\
(100,00)\end{array}$ & $\begin{array}{r}61 \\
(32,97)\end{array}$ & $\begin{array}{r}111 \\
(60,00)\end{array}$ & $\begin{array}{r}13 \\
(7,03)\end{array}$ & $\begin{array}{r}185 \\
(100,00)\end{array}$ \\
\hline Rio Grande do Norte & $\begin{array}{r}38 \\
(22,75)\end{array}$ & $\begin{array}{r}104 \\
(62,28)\end{array}$ & $\begin{array}{r}25 \\
(14,97)\end{array}$ & $\begin{array}{r}167 \\
(100,00)\end{array}$ & $\begin{array}{r}66 \\
(39,52)\end{array}$ & $\begin{array}{r}94 \\
(56,29)\end{array}$ & $\begin{array}{r}7 \\
(4,19)\end{array}$ & $\begin{array}{r}167 \\
(100,00)\end{array}$ \\
\hline Sergipe & $\begin{array}{r}21 \\
(28,00) \\
\end{array}$ & $\begin{array}{r}43 \\
(57,33) \\
\end{array}$ & $\begin{array}{r}11 \\
(14,67) \\
\end{array}$ & $\begin{array}{r}75 \\
(100,00) \\
\end{array}$ & $\begin{array}{r}25 \\
(33,33) \\
\end{array}$ & $\begin{array}{r}49 \\
(65,33) \\
\end{array}$ & $\begin{array}{r}1 \\
(1,34) \\
\end{array}$ & $\begin{array}{r}75 \\
(100,00) \\
\end{array}$ \\
\hline CENTRO-OESTE & $\begin{array}{r}118 \\
(25,32)\end{array}$ & $\begin{array}{r}272 \\
(58,37)\end{array}$ & $\begin{array}{r}76 \\
(16,31)\end{array}$ & $\begin{array}{r}466 \\
(100,00)\end{array}$ & $\begin{array}{r}122 \\
(26,18)\end{array}$ & $\begin{array}{r}266 \\
(57,08)\end{array}$ & $\begin{array}{r}78 \\
(16,74)\end{array}$ & $\begin{array}{r}466 \\
(100,00)\end{array}$ \\
\hline Goiás & $\begin{array}{r}53 \\
(21,54)\end{array}$ & $\begin{array}{r}152 \\
(61,79)\end{array}$ & $\begin{array}{r}41 \\
(16,67)\end{array}$ & $\begin{array}{r}246 \\
(100,00)\end{array}$ & $\begin{array}{r}56 \\
(22,76)\end{array}$ & $\begin{array}{r}143 \\
(58,13)\end{array}$ & $\begin{array}{r}47 \\
(19,11)\end{array}$ & $\begin{array}{r}246 \\
(100,00)\end{array}$ \\
\hline Mato Grosso & $\begin{array}{r}45 \\
(31,91)\end{array}$ & $\begin{array}{r}78 \\
(55,32)\end{array}$ & $\begin{array}{r}18 \\
(12,77)\end{array}$ & $\begin{array}{r}141 \\
(100,00)\end{array}$ & $\begin{array}{r}39 \\
(27,66)\end{array}$ & $\begin{array}{r}81 \\
(57,45)\end{array}$ & $\begin{array}{r}21 \\
(14,89)\end{array}$ & $\begin{array}{r}141 \\
(100,00)\end{array}$ \\
\hline Mato Grosso do Sul & $\begin{array}{r}20 \\
(25,64)\end{array}$ & $\begin{array}{r}41 \\
(52,56)\end{array}$ & $\begin{array}{r}17 \\
(21,79)\end{array}$ & $\begin{array}{r}78 \\
(100,00)\end{array}$ & $\begin{array}{r}27 \\
(34,62)\end{array}$ & $\begin{array}{r}41 \\
(52,56)\end{array}$ & $\begin{array}{r}10 \\
(12,82)\end{array}$ & $\begin{array}{r}78 \\
(100,00)\end{array}$ \\
\hline Distrito Federal & $\begin{array}{r}0 \\
(0,00)\end{array}$ & $\begin{array}{r}1 \\
(100,00)\end{array}$ & $\begin{array}{r}0 \\
(0,00)\end{array}$ & $\begin{array}{r}1 \\
(100,00)\end{array}$ & $\begin{array}{r}0 \\
(0,00)\end{array}$ & $\begin{array}{r}1 \\
(100,00)\end{array}$ & $\begin{array}{r}0 \\
(0,00)\end{array}$ & $\begin{array}{r}1 \\
(100,00)\end{array}$ \\
\hline TOTAL & $\begin{array}{r}1386 \\
(24,91)\end{array}$ & $\begin{array}{r}2783 \\
(50,01)\end{array}$ & $\begin{array}{r}1396 \\
(25,09)\end{array}$ & $\begin{array}{r}5565 \\
(100,00)\end{array}$ & $\begin{array}{r}1399 \\
(25,14)\end{array}$ & $\begin{array}{r}2896 \\
(52,04)\end{array}$ & $\begin{array}{r}1270 \\
(22,82)\end{array}$ & $\begin{array}{r}5565 \\
(100,00)\end{array}$ \\
\hline
\end{tabular}

Fonte: Elaboração própria.

Nota: S - Satisfatório; R - Regular; I - Insatisfatório. 
No ciclo de vida da criança, verifica-se que a região Sul (31,56\%) é a que detém o maior percentual de municípios considerados satisfatórios - e destaque para Santa Catarina como o estado com o maior percentual de municípios considerados satisfatórios nesse ciclo de vida, com $42,32 \%$-, seguida pelas regiões Sudeste (29,86\%), Centro-Oeste (27,48\%), Nordeste $(19,34 \%)$ e Norte $(10,02 \%)$.

Para o ciclo de vida do adolescente, observa-se que a região Sudeste $(39,51 \%)$ é a que detém o maior percentual de municípios considerados satisfatórios, seguida pelas regiões Sul $(35,35 \%)$, Centro-Oeste $(20,60 \%)$, Nordeste $(11,26 \%)$ e Norte (4,90\%). O estado de Minas Gerais contém o maior percentual de municípios considerados satisfatórios nesse ciclo de vida, com $46,78 \%$, e o estado do Amapá destaca-se por ter $100 \%$ dos municípios insatisfatórios.

Destaca-se para o ciclo do adulto os estados do Maranhão e do Piauí, que tiveram mais que $50 \%$ dos seus municípios considerados insatisfatórios.
As regiões Sul e Sudeste tiveram o pior desempenho quando comparadas com as outras regiões, no ciclo de vida do idoso, com $19,19 \%$ e $16,61 \%$, respectivamente, dos municípios considerados satisfatórios.

O estado de Roraima não teve nenhum município considerado satisfatório em todos os ciclos de vida.

A tabela 3 apresenta o desempenho global das regiões do País, a partir do indicador sintético de avaliação do desempenho, com a quantidade de municípios classificados como satisfatórios, regulares e insatisfatórios. Observa-se que a região Sul tem o maior percentual de municípios considerados satisfatórios (31,57\%), seguida pela região Sudeste $(30,28 \%)$, Centro-Oeste (29,40\%), Nordeste (19,06\%) e Norte $(7,80 \%)$. Destaca-se que os estados do Acre, Amapá, Pará, Roraima, Bahia e Piauí tiveram mais de $50 \%$ de seus municípios classificados como insatisfatórios. Roraima não apresentou nenhum município classificado como satisfatório, e o Pará apenas um município nessa condição.

Tabela 3. Classificação dos municípios por região, conforme o desempenho no Provimento da Atenção Básica. Brasil, 2012

\begin{tabular}{lcccccc}
\hline & \multicolumn{2}{c}{ Satisfatório } & \multicolumn{2}{c}{ Regular } & \multicolumn{2}{c}{ Insatisfatório } \\
\cline { 2 - 6 } Região & $\mathbf{n}$ & $\%$ & $\mathbf{n}$ & \% & $\mathbf{n}$ & $\%$ \\
\hline Sul & 375 & 31,57 & 588 & 49,49 & 225 & 18,94 \\
Sudeste & 505 & 30,28 & 882 & 52,88 & 281 & 16,85 \\
Centro-Oeste & 137 & 29,40 & 226 & 48,50 & 103 & 22,10 \\
Norte & 35 & 7,80 & 199 & 44,32 & 215 & 47,88 \\
Nordeste & 342 & 19,06 & 878 & 48,94 & 574 & 32,00 \\
\hline TOTAL & 1394 & 25,1 & 2773 & 49,8 & 1398 & 25,1 \\
\hline
\end{tabular}

Fonte: Elaboração própria.

\section{Discussão}

O presente estudo identificou o desempenho da $\mathrm{AB}$ nos municípios brasileiros, que foram agrupados por estados, considerando o Provimento da Atenção Básica nos ciclos de vida e o desempenho global nesta dimensão, com destaque para as regiões Sul e Sudeste, que tiveram os melhores resultados.

O desempenho municipal no Provimento da Atenção Básica tem sido avaliado em diferentes estados e regiões, a partir de estudos, como os de linha de base do Proesf, 
e a partir de iniciativas institucionais do Ministério da Saúde, com o financiamento de vários projetos de pesquisa que têm como objeto a avaliação da $\mathrm{AB}$, fortalecendo sua institucionalização no SUS (ALMEIDA; GIOVANELLA, 2008). Contudo, não há estudos publicados que avaliam o desempenho de todos os municípios brasileiros na $\mathrm{AB}$ aplicando-se a mesma metodologia de avaliação. o Índice de Desempenho do SUS (IDSUS) emite uma pontuação para os municípios, mas não tem como objeto a $\mathrm{AB}$, abrangendo a média e alta complexidade também. O Proadess - Metodologia de Avaliação do Desempenho do Sistema de Saúde - embora tenha componentes de avaliação da $\mathrm{AB}$, analisa estados e regiões do Brasil sem desagregação por municípios. Com relação a esses estudos, destacam-se alguns de seus resultados que contribuem na discussão dos resultados aqui encontrados.

No Relatório do Proadess (ICICT, 2012), é destacada a melhoria no desempenho do sistema de saúde brasileiro na última década, principalmente nas regiões com maior expansão da ESF. Entretanto, assim como no presente estudo, o comportamento dos indicadores não foi uniforme, com fortes disparidades regionais desfavoráveis às regiões mais pobres. $\mathrm{Na}$ atenção à saúde do adolescente, por exemplo, a região Sudeste teve $39,6 \%$ dos municípios classificados como satisfatórios, enquanto a região Norte teve apenas $4,9 \%$. As dimensões continentais e as grandes desigualdades entre as regiões do Brasil se expressam na distribuição da população, nos aspectos sociais e econômicos, culminando com alguns problemas dos quais destaca-se a dificuldade de associar a demanda que existe por bens e serviços públicos com a capacidade local de financiamento, evidenciando a deficiência do acesso e das propostas de ações e serviços que não atendem às reais necessidades da população, especificamente na área da saúde (LUIZ ET AL., 2009; SIMÃO; ORELLANO, 2015).
A proposta de fortalecer a Atenção Primária à Saúde é uma estratégia para reorganizar o sistema de saúde, principalmente entre os países em desenvolvimento. No Brasil, mesmo com os esforços de priorizar as ações básicas por meio de incentivo ao modelo da ESF e da utilização do critério per capita de financiamento para transferência de recursos da União para os municípios e regiões, essas medidas ainda se mostram insuficientes diante da capacidade de oferta dos serviços de saúde e da distribuição desigual existente entre as regiões, assim como dentro das próprias regiões, que influenciam de modo importante o acesso (FAHEL; NEVES, 2009). Por exemplo, na saúde do adulto, dentro da região Sudeste, o Rio de Janeiro teve $41 \%$ dos seus municípios insatisfatórios, contra apenas 7\% dos municípios de São Paulo na mesma condição.

Alguns indicadores são capazes de evidenciar outros aspectos que vão além do setor da saúde, apontando para a qualidade de vida de determinada população. Como exemplo, tem-se o indicador de mortalidade infantil, que mantém forte associação com indicadores socioeconômicos, revelando que a renda, escolaridade, saneamento básico, abastecimento de água potável, PIB per capita, investimento na saúde, acessibilidade da população aos serviços de saúde, nível de informação, proteção social, entre outros, influenciam no aumento ou redução desse indicador (DUARTE, 2007; FISCHER ET AL., 2007). Sendo assim, para as crianças, a identificação dos diferentes desempenhos que existem nas regiões brasileiras podem ser analisadas quanto à capacidade que os serviços de saúde têm tido em superar as desigualdades em qualidade de vida. Observa-se que nas regiões Sul e Sudeste, onde encontram-se melhores condições de vida e acesso aos serviços de saúde, estão concentrados os maiores percentuais de municípios com desempenho satisfatório. O objetivo de garantir o direito à vida para toda criança brasileira ainda não foi atingido porque ainda existem 
desigualdades regionais e sociais capazes de influenciar nessa meta (BRASIL, 2012).

Para os ciclos de vida do adolescente e do adulto, o Sudeste registra o maior percentual em relação às outras regiões, tendo em vista os municípios considerados como satisfatórios com $39,51 \%$ e $46,78 \%$ respectivamente.

O desempenho na saúde do adolescente teve as maiores desigualdades regionais entre os ciclos de vida. No documento 'Diretrizes nacionais para a atenção integral à saúde de adolescentes e jovens na promoção, proteção e recuperação da saúde' (BRASIL, 2010), é apresentada uma análise da situação de saúde de adolescentes e jovens no Brasil, evidenciando dificuldades de acesso à educação, o desemprego, as profundas desigualdades sociais, a morbimortalidade por violências, entre outras, apontando para o impacto causado na saúde de pessoas jovens. Essas condições tornam os adolescentes uma população vulnerável aos agravos resultantes do uso abusivo de álcool e de outras drogas e das violências; de doenças sexualmente transmissíveis e Aids; à mortalidade materna; na saúde sexual e na saúde reprodutiva, ao início ou ao estabelecimento de doenças crônicas, o que interfere no crescimento e desenvolvimento saudáveis. O documento aponta que o risco de ser mãe até os 14 anos é $60 \%$ maior entre adolescentes negras, e mais comum nos municípios menores e de baixa renda, onde $22 \%$ das adolescentes grávidas realizaram menos de 4 consultas de pré-natal. Também indica que a vulnerabilidade é maior nas regiões Norte e Centro-Oeste.

A elaboração de políticas públicas direcionadas à população mais vulnerável tem colaborado para melhorar os indicadores de saúde. No caso da saúde da mulher, verifica-se que a mortalidade materna não é apenas um indicador sensível de qualidade de vida da população; além disso, indica o nível de respeito aos direitos sexuais e reprodutivos na comunidade. A mortalidade materna não está associada somente ao acesso aos serviços de saúde, mas também à sua qualidade e à dos procedimentos realizados, às desigualdades e iniquidades sociais (BRASIL, 2004; BRASIL, 2006). Uma comparação entre os anos 2000 e 2009 indicou que no Brasil houve um aumento de $11,92 \%$ no número absoluto de mortes maternas, destacando o aumento diferente nas regiões Norte, que apresentou um crescimento de 15,46\%; o Nordeste, 18,53\%; o Sudeste, $10,31 \%$; e o Centro-Oeste, $50,54 \%$ no número absoluto de mortes maternas. Entretanto, a região Sul apresentou uma redução, em números absolutos, correspondente a $15,76 \%$ (FERRAZ; BORDIGNON, 2012).

$O$ desempenho da $\mathrm{AB}$ pode ser medido pelo uso do indicador Internações por Condições Sensíveis à Atenção Primária (ICSAP) que sinaliza a efetividade da AB, já que é nesse nível de atenção que as doenças listadas pela ICSAP poderiam ser resolvidas, evitando, assim, internações hospitalares e, consequentemente, um aumento de gastos com saúde (ALFRADIQUe ET AL., 2009; FERREIRA ET AL., 2014). As internações por Condições Sensíveis à Atenção Primária (CSAP) no Brasil, no período de 1998 a 2009, apresentaram uma diminuição significativa, sendo que os resultados mais expressivos foram encontrados nos estados de Sergipe, Rondônia, Mato Grosso, Santa Catarina e Pernambuco. Para os estados do Acre, Amazonas, Roraima, Amapá, Goiás e o Distrito Federal, houve estabilidade das internações. Em nenhum estado houve acréscimo nas internações por CSAP no período analisado (BOING ET AL., 2012). Esses resultados corroboram o desempenho satisfatório dos municípios encontrados nos estados de Sergipe, Mato Grosso, Santa Catarina e Pernambuco tanto para o ciclo de vida do adulto quanto para o ciclo de vida do idoso.

Quanto ao ciclo de vida do idoso, este estudo registrou que a região Nordeste, seguida pela região Norte e Centro-Oeste, possui o maior percentual de municípios considerados satisfatórios. Esse dado leva 
a uma reflexão sobre o acesso ao serviço de saúde ofertado na $\mathrm{AB}$. Dos cinco indicadores selecionados para esse ciclo, dois consideram a não internação como um fator positivo, porém, se a população não está tendo acesso às internações, principalmente pela falta de leitos hospitalares, as taxas de não internação nos municípios com essa situação ficam muito altas, 'favorecendo' seu desempenho. Mafra (2011) realizou um estudo com o objetivo de avaliar de que modo a expansão da $\mathrm{AB}$ em saúde tem afetado as taxas de internações hospitalares por condições sensíveis. Para as regiões Norte e Nordeste, a maior cobertura dos Agentes Comunitários de Saúde (ACS) estava acompanhada de maiores taxas de internação. $\mathrm{O}$ autor considera que nas regiões em que há carência de serviços de saúde em geral, a $\mathrm{AB}$, por meio do trabalho desenvolvido pelos ACS, fortemente baseado no atendimento em domicílio da população, pode estar funcionando como um elemento identificador e facilitador das internações hospitalares.

O envelhecimento da população é uma realidade que tem um grande impacto na saúde pública, já que as demandas pelos serviços de saúde podem representar custos mais elevados. A fratura de fêmur tem tido uma atenção das autoridades sanitárias mediante seu impacto, além do sistema de saúde, na qualidade de vida dos idosos. No período de 2008 a 2012, foram avaliados os dados secundários que estão registrados no Sistema de Informações Hospitalares do Sistema Único de Saúde (SIH-SUS) sobre a distribuição de fraturas de fêmur ocorridas no Brasil, e constatou-se uma maior incidência de fraturas de fêmur na população idosa na região Sudeste, com $54,7 \%$ de todos os casos, e a região Norte foi a que teve menor incidência, com 3,5\% dos casos (SOARES ET AL., 2014).

Entre todos os 26 estados e o Distrito Federal, o estado de Roraima não registrou nenhum município considerado satisfatório. De acordo com relatos das atividades do PMAQ-AB em 2012, Roraima exibe unidades de saúde em condições adequadas para atender à sua população, entretanto, em muitos municípios, as condições, no que se refere à estrutura e à operacionalização das ações de saúde, não atingem o padrão mínimo de qualidade. O cenário encontrado revela os conflitos existentes entre a gestão e a execução das ações em saúde (LOUZADA; RAMOS, 2013).

Ressalta-se que a análise de desempenho a partir da metodologia aqui apresentada considera o desempenho relativo entre municípios de mesmo porte. Desse modo, os municípios classificados como satisfatórios apresentam um bom desempenho na $\mathrm{AB}$ quando comparados com os demais municípios de seu porte, porém, não necessariamente apresentam um bom Provimento da Atenção Básica, já que os parâmetros dos indicadores não são normativos. É difícil estabelecer parâmetros nacionais para todos os indicadores que se apliquem a todos os municípios. Por esta metodologia, considera-se como melhor desempenho no indicador o melhor valor que alguém conseguiu atingir no conjunto de municípios avaliados (dentro de cada porte). Esta análise traz uma perspectiva de estabelecer metas factíveis para os municípios avaliados, que devem utilizar os resultados dessa avaliação para o direcionamento de suas ações na AB.

\section{Considerações finais}

Embora sigam as mesmas diretrizes e legislações para estruturação da $\mathrm{AB}$, as ações que a gestão municipal prioriza são diferentes em cada município, constituindo diferentes formas de organização que por sua vez produzem diferentes resultados na saúde da população. De qualquer forma, espera-se que a $\mathrm{AB}$ garanta o Provimento à saúde da população em todos os ciclos de vida (criança, adolescente, adulto e idoso), reduzindo o risco de doenças e de outros agravos. Em Santa Catarina, a avaliação 
do desempenho dos municípios a partir desta metodologia tem sido valorizada pela gestão estadual, que premia aqueles com melhores desempenhos. Observa-se que aqueles com piores desempenhos têm buscado melhorias na estruturação da $\mathrm{AB}$, fazendo com que a avaliação cumpra seu papel indutor de mudanças e subsidiário à tomada de decisão, nesse caso no âmbito municipal. $\mathrm{O}$ fato de estarem sendo avaliados a partir de parâmetros factíveis e não normativos, sendo comparados com municípios de mesmo porte, com condições de gestão mais semelhantes, parece estimulá-los a alcançar melhores desempenhos.

\section{Referências}

ALFRADIQUE, M. E. et al. Internações por condições sensíveis à atenção primária: a construção da lista brasileira como ferramenta para medir o desempenho do sistema de saúde (Projeto ICSAP - Brasil). Cad. Saúde Pública, Rio de Janeiro, n. 25, v. 6, jun. 2009, p. 1337-1349.

ALMEIDA, P. F.; GIOVANELLA, L. Avaliação em Atenção Básica à Saúde no Brasil: mapeamento e análise das pesquisas realizadas e/ou financiadas pelo Ministério da Saúde entre os anos de 2000 e 2006. Cad. Saúde Pública, Rio de Janeiro, v. 24, n. 8, ago. 2008, p. 1727-1742.

BODSTEIN, R. Atenção Básica na agenda da saúde. Ciênc. saúde coletiva, v. 7, n. 3, p. 401-412, 2002.

BOING, A. C. et al. Redução das Internações por Condições Sensíveis à Atenção Primária no Brasil entre 1998-2009. Rev. Saúde Pública, v. 46, n. 2, p. 359-366, 2012.

BRASIL. Ministério da Saúde. Painel de indicadores do SUS, Brasília, DF, ano I, n. 1, 2006. Disponível em: $<$ http://www.redeblh.fiocruz.br/media/indicadsusl. pdf $>$. Acesso em: 27 mar. 2015.

. Ministério da Saúde. Secretaria de Atenção

à Saúde. Departamento de Ações Programáticas Estratégicas. Pacto nacional pela redução da
$\mathrm{Na}$ impossibilidade de publicar neste trabalho o desempenho de cada município, optou-se por agregar os dados por estados e regiões, embora o banco de dados tenha sido estruturado de forma a emitir juízo de valor para cada município do Brasil.

Os resultados evidenciam as discrepâncias entre as regiões do País, reforçando a influência que fatores de desenvolvimento econômico e social exercem sobre a estruturação do sistema de saúde e apontando a necessidade de reestruturação desse nível de atenção, principalmente nos municípios das regiões com piores desempenhos. mortalidade materna e neonatal. 2004. Disponível em: $<$ http://www.saude.ba.gov.br/dab/Pacto_Aprovado_na_ tripartite.pdf>. Acesso em: 27 nov. 2015.

Ministério da Saúde. Secretaria de Atenção à Saúde. Departamento de Atenção Básica. Saúde da criança: crescimento e desenvolvimento. Brasília, DF: Ministério da Saúde, 2012.

Ministério da Saúde. Secretaria de Atenção em Saúde. Departamento de Ações Programáticas Estratégicas. Diretrizes nacionais para a atenção integral à saúde de adolescentes e jovens na promoção, proteção e recuperação da saúde. Brasília, DF: Ministério da Saúde, 2010.

CASTRO, A. L. B.; MACHADO, C. V. A política de atenção primária à saúde no Brasil: notas sobre a regulação e o financiamento federal. Cad. Saúde Pública, Rio de Janeiro, v. 26, n. 4, p. 693-705, 2010.

DUARTE, C. M. R. A. Reflexos das políticas de saúde sobre as tendências da mortalidade infantil no Brasil: revisão da literatura sobre a última década. Cad. Saúde Pública, Rio de Janeiro, v. 23, n. 7, p. 1511-1528, 2007.

FACCHINI, L. A. et al. Avaliação de efetividade da Atenção Básica à Saúde em municípios das regiões Sul 
e Nordeste do Brasil: contribuições metodológicas. Cad. Saúde Pública, Rio de Janeiro, v. 24, supl. 1, p. 159$172,2008$.

FAHEL, M.; NEVES, J. A. B. Desigualdades em Saúde no Brasil: análise comparada do acesso aos serviços de saúde por estratos ocupacionais. Teoria e sociedade, Belo Horizonte, n. 17.2, p. 140-159, 2009.

FERRAZ, L.; BORDIGNON, M. Mortalidade materna no Brasil: uma realidade que precisa melhorar. Revista Baiana de Saúde Pública, Salvador, v. 36, n. 2, p. $527-538,2012$

FERREIRA, J. B. B. et al. Internações por condições sensíveis à atenção primária à saúde em uma região de saúde paulista, 2008 a 2010. Epidemiol. Serv. Saúde, Brasília, DF, v. 1, n. 23, p. 45-56, 2014.

FISCHER, T. K. A mortalidade infantil no brasil: série histórica entre 1994-2004 e associação com indicadores socioeconômicos em municípios de médio e grande porte. Medicina, Ribeirão Preto, v. 40, n. 4, p. 559-566, 2007.

HENRIQUE, F.; CALVO, M. C. M. Grau de implantação do Programa Saúde da Família e indicadores sociais. Ciênc. saúde coletiva, Rio de Janeiro, v. 14, supl. 1, p. 1359-1365, 2009.

\section{INSTITUTO DE COMUNICAÇÃO E} INFORMAÇÃO EM CIÊNCIA E TECNOLOGIA (ICICT). Relatório PROADESS: avaliação de desempenho do sistema de saúde brasileiro: indicadores para monitoramento. 2012. Disponível em: <http:// www.proadess.icict.fiocruz.br/SGDP-RELATORIO_ FINAL\%20_com_sumario_atualizadorev\%202014. pdf $>$. Acesso em: 27 nov. 2015.

LOUZADA, J.; RAMOS, R. L. Roraima: Roraima e seus quintais. In: FAUSTO, M. C. R.; FONSECA, H. M. S. (Org.). Rotas da Atenção Básica no Brasil: experiências do trabalho de campo PMAQ-AB. Rio de Janeiro: Saberes Editora, 2013.
LUIZ, O. C. et al. Diferenciais intermunicipais de condições de vida e saúde: construção de um indicador composto. Rev. Saúde Pública, São Paulo, v. 43, n. 1, p. 115-122, 2009.

MAFRA, F. O impacto da Atenção Básica em saúde em indicadores de internação hospitalar no Brasil. 2010. 129 f. Dissertação (Mestrado em Regulação e Gestão de Negócios) - Universidade de Brasília, Brasília. 2010.

NICKEL, D. A. et al. O uso de uma avaliação por gestores da atenção primária em saúde: um estudo de caso no Sul do Brasil. Cad. Saúde Pública, Rio de Janeiro, v. 30, n. 12, p. 2619-2630, 2014.

SCARATTI, D. Um modelo para avaliar a qualidade da gestão municipal da atenção básica à saúde no Brasil: uma aplicação a municípios catarinenses. 2007. 315 p. Tese (Doutorado em Engenharia de Produção) - Programa de Pós-Graduação em Engenharia de Produção, Universidade Federal de Santa Catarina, Florianópolis. 2007.

SIMÃO, J. B.; ORELLANO, V. I. F. Um estudo sobre a distribuição das transferências para o setor de saúde no Brasil. Estud. Econ., São Paulo, v. 45, n. 1, 2015, p. 33-63.

SOARES, D. S. et al. Fraturas de fêmur em idosos no Brasil: análise espaço-temporal de 2008 a 2012. Cad. Saúde Pública, Rio de Janeiro, v. 30, n. 12, p. 2669-2678, 2014.

TANAKA, O. Y.; MELO, C. Uma proposta de abordagem transdisciplinar para avaliação em Saúde. Interface (Botucatu), Botucatu, v. 4, n. 7, p. 113-118, 2000.

VIEIRA, J. M. R.; GARNELO, L.; HORTALE, V. A. Análise da Atenção Básica em cinco municípios da Amazônia Ocidental, com ênfase no Programa Saúde da Família. Saúde Soc., São Paulo, v. 19, n. 4, p. $852-865,2010$.

Recebido para publicação em maio de 2015

Versão final em julho de 2015

Conflito de interesses: inexistente

Suporte financeiro: não houve 